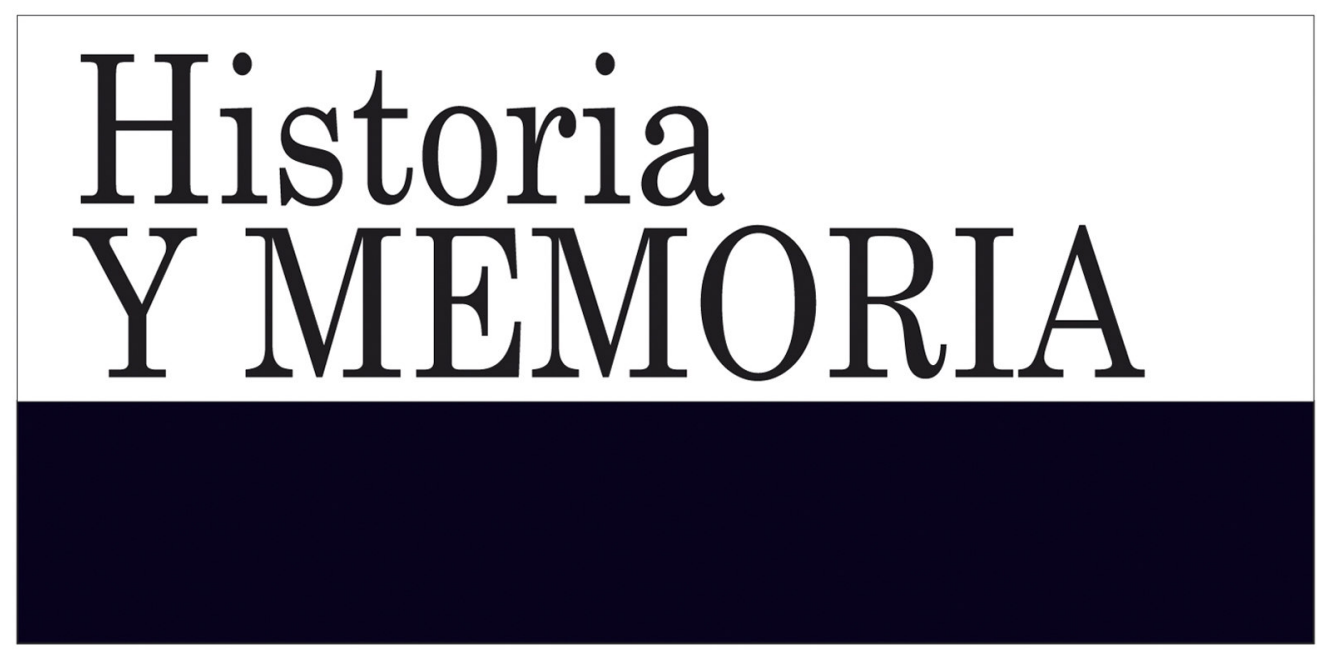

ISSN: 2027-5137 Julio - Diciembre, Año 2014 - Tunja, Colombia

E1 Pasado: Historia o Memoria

Olga Yanet Acuña Rodriguez Páginas: 57 - 87

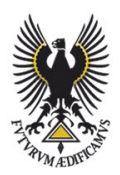




\title{
El Pasado: Historia o Memoria
}

\author{
Olga Yanet Acuña Rodríguez ${ }^{1}$ \\ Universidad Pedagógica y Tecnológica de Colombia
}

Recepción: 30/06/2014

Evaluación: 07/02/2014

Aceptación: 18/08/2014

Artículo de Investigación e Innovación.

\section{Resumen}

Este artículo reflexiona sobre la relación entre historia y memoria como fundamentos del conocimiento del pasado. El texto se interesa, en primer lugar, por la diferenciación entre memoria e historia, que si bien son instrumentos al servicio de la construcción del pasado, tienen entre sí diferencias relevantes, las cuales en la actualidad han sido estudiadas desde distintos campos —no exclusivamente el histórico-, que han permitido abrir un debate académico e intelectual fascinante. En segundo lugar, es analizada la manera como se han abordado estos dos conceptos en los primeros seis números de la Revista Historia Y MEMORIA, con lo cual se propone, desde la historiografía, un campo de análisis que le permita a los investigadores en ciencias sociales dialogar sobre los aportes de la memoria a la construcción historiográfica y cómo la memoria contribuye a fijar un recuerdo individual y colectivo. En los seis números de la revista la relación entre historia y memoria se ha podido apreciar desde las temáticas, los enfoques, el uso de fuentes y las metodologías planteadas,

1 Doctora en Historia, Universidad Pablo de Olavide, España. Docente Doctorado en Historia y Escuela de Ciencias Sociales, Universidad Pedagógica y Tecnológica de Colombia. Editora Revista Historia y Memoria. Grupo de Investigación: Asociación Centro de Estudios Regionales. Líneas de investigación: Universidad, ciudadanía y nación, ciudadanía y violencia. olga.acuna@uptc.edu.co 
acercándonos a otras visiones sobre el pasado, pero en un diálogo permanente con el presente.

Palabras clave: historia, memoria, conocimiento, pasado, Revista Historia y MEMORIA.

\section{The Past: History or Memory}

\section{Summary}

This article considers the connection between history and memory as foundations for knowledge of the past. Firstly, this article is interested in the differentiation between memory and history. Regardless of the fact that both of these are effective tools for the reconstruction of the past, memory and history have relevant differences which have been studied from multiple viewpoints - not exclusively a historical one -, facilitating a fascinating academic and intellectual debate. Secondly, this article analyzes the way in which these two concepts have been addressed in the first six issues of Historia $Y$ MEMORIA journal, which proposes historiography, as a field of analysis that allows researchers in the social sciences to discuss the contributions of memory to historiographical construction, and how memory contributes to the creation of both individual and collective remembrance. In the first six journal issues, the relationship between history and memory is found in the subject matter, theoretical approaches, use of sources and proposed methodologies, bringing us closer to alternative prognoses about the past, that include a permanent dialogue with the present.

Key words: history, memory, knowledge, past, Historia $Y$ MEMORIA journal. 


\section{Le passé: histoire ou mémoire}

\section{Résumé}

Cet article porte sur le lien entre histoire et mémoire comme fondement de la connaissance du passé. Le texte s'intéresse, d'abord, à la différenciation entre mémoire et histoire, qui bien qu'ils soient des instruments au service de la construction du passé, ont entre eux des différences significatives, lesquelles ont été étudiées actuellement dans différents domaines - pas exclusivement l'histoire-, qui ont permis d'ouvrir un débat académique et intellectuel fascinant. Deuxièmement est analysée la manière dont on a abordé ces deux concepts dans les six premiers numéros de la revue Histoire ET MÉMOIRE, et par la suite on propose, à partir de l'historiographie, un domaine d'analyse qui permet aux chercheurs en sciences sociales de dialoguer sur les contributions de la mémoire à la construction historiographique et comment la mémoire contribue à fixer un souvenir individuel et collectif. Dans les éditions de la revue, la relation entre histoire et mémoire a été considérée à partir des thématiques, des analyses, de l'utilisation de sources et des méthodologies utilisées, ce qui nous permet de nous approcher à d'autres interprétations du passé, dans un dialogue permanent avec le présent.

Mots clés: histoire, mémoire, connaissance, passé, revue Histoire ET MÉMOIRE.

\section{Introducción}

El artículo parte de una reflexión teórica sobre la memoria, se pretende acercar al lector a algunos debates sobre el conocimiento del pasado bajo la comprensión de historia y memoria. Con estas reflexiones se lleva a indagar por la forma como desde la historiografía se ha planteado el análisis del pasado; de esta manera se invita al historiador a investigar no solo por lo que pasó, sino por lo que los actores sociales recuerdan y por la manera como ellos han fijado esos recuerdos; asimismo por las intencionalidades que se desligan del recuerdo y del olvido. 
Se partió de la revisión del concepto de historia y memoria en libros y artículos desde perspectivas diversas, lo que nos aportó reflexiones teóricas interesantes sobre el concepto de memoria como 'lugar colectivo', como apropiación 'individual', como fijación o derivación del 'recuerdo', que han sido un referente sustancial para los análisis que se han planteado desde la historiografía. En un segundo momento se retomaron los 6 primeros números de la Revista Historia y Memoria para tratar de comprender cómo la historia y la memoria estuvieron presentes en las construcciones historiográficas, ya desde la metodología, desde las temáticas abordadas, desde el tipo de fuente y su respectivo análisis, en términos generales desde las voces de los 'otros'. En este sentido, es importante indagar por la forma como se ha construido el objeto en el tiempo, mirar la construcción de ese hecho histórico y la manera en que ha sido transmitido; lo que implica a la vez tratar de comprender cómo el poder es capaz de construir y legitimar el pasado.

Esta reflexión nos permite dejarle al lector un camino para el análisis y para la comprensión de la realidad, en una relación dialógica pasado-presente, en la que se pueda vislumbrar que el historiador también participa en la construcción de la memoria individual y colectiva, porque con el resultado de su investigación aporta nuevas reflexiones sobre un hecho, y en su transmisión puede incidir en las reflexiones para la comprensión de la sociedad del momento. A continuación desarrollaremos los dos apartes en que se compone el artículo: Reflexiones sobre los conceptos Historia y Memoria e Historia y Memoria en debate.

\section{Reflexiones sobre los conceptos Historia y Memoria}

Los debates suscitados han generado nuevas interpretaciones sobre la relación entre memoria e historia, son diversas las acepciones que al respecto se han planteado y que pretenden darle un sentido distinto al papel del sujeto, al colectivo social, al recuerdo individual y colectivo.

Partimos de algunos interrogantes que han orientado esta reflexión: ¿Por qué debatir hoy sobre la Historia y la 
Memoria? ¿Es la Memoria un proceso diferenciado de la Historia en relación con la construcción de los hechos del pasado? ¿El recuerdo es una actividad de carácter previo a la construcción histórica del paso del tiempo? Estos aspectos han sido abordados desde disciplinas como Historia, Antropología, Sociología y Filosofía, las que se han ocupado de analizar la interrelación de estos dos campos del conocimiento para la comprensión de la realidad social. Sin duda, la obra del desaparecido filósofo francés Paul Ricoeur, La Mémoire, l'histoire, l'oubli, editada en francés en el año de $2000^{2}$, ha configurado un referente de primer orden para poner el debate abierto entre Historia y Memoria. En su primer capítulo, Ricoeur parte de dos preguntas de carácter fenomenológico ${ }^{3}$, que son guías y orientan su larga e importante reflexión sobre estos dos fenómenos: “¿De qué hay recuerdo? ¿De quién es la memoria?"4. Es interesante como el filósofo francés parte, a su vez, de establecer el recuerdo como un fenómeno propio de algo más estructurado: la Memoria. Y cómo en relación con el recuerdo, es importante el qué objetual, mientras que en relación con la Memoria, el interés se centra en el carácter posesivo de la misma; es decir, como afirma el mismo autor, "centrada en la apropiación del recuerdo por un sujeto capaz de acordarse de sí";; un sujeto constructor de su pasado y, por lo tanto de su propia historia, tanto como sujeto individual (historia de vida), como colectivamente en tanto la memoria es compartida, "vivida" y defendida o repudiada por sociedades y colectividades; podría decirse que es el paso del recuerdo a la memoria reflexiva, pasando por la reminiscencia.

2 Hemos utilizado la edición en castellano Paul Ricoeur, La memoria, la historia, el olvido (Madrid: Editorial Trotta, 2003).

3 Las tendencias más profesionalizadas de la Historia han tendido un largo olvido sobre el carácter fenomenológico de esta disciplina. Hoy en día el debate entre Historia y Memoria ha puesto de nuevo de relieve esta tendencia fenomenológica como un instrumento metodológico de primer orden, capaz de acercarnos a problemas complejos sobre el recuerdo y la construcción del mismo convertido en hecho histórico.

4 Paul Ricoeur, La memoria, la historia...19.

5 Paul Ricoeur, La memoria, la historia...20. 
Pero, ¿qué es la Historia y cuál es la relación con la Memoria? Al respecto, Josefina Cuesta Bustillo ${ }^{6}$ plantea que la Historia es entendida como el saber científico de los hechos pasados, el rigor de control de los testimonios; mientras que la Memoria es el recuerdo de estos hechos pasados cultivada por los contemporáneos y sus descendientes. Esto generó interpretaciones que plantearon una distinción de conjunto entre la disciplina científica y la construcción social de la memoria, que inciden en la configuración de los recuerdos que construyen los grupos sobre su propia realidad. En palabras del historiador mexicano Enrique Florescano ${ }^{7}$, la Memoria es una categoría que alimenta a la historia y prácticamente es el fundamento central de la historia. La Historia es el centro del recuerdo que se alimenta con la Memoria, pero que depende de las percepciones, los constructos y en general de la visión del historiador. Los planteamientos de Florescano son sugerentes para nuestro análisis porque dimensionan el papel sociedad como componente central del estudio de la Historia, lo que la convierte en una disciplina social que se alimenta de la memoria individual y colectiva.

Por su parte, Paul Ricoeur en su texto La Memoria, la Historia, el Olvido, plantea que la Historia y la Memoria tienen una relación dialéctica con la que se explica el pasado en relación con el presente; la Memoria es la capacidad de recorrer y de remontar los hechos en el pasado y establecer un vínculo con el presente, mientras que la Historia se sitúa en un espacio de confrontación de diversos testimonios y con diferentes grados de fiabilidad ${ }^{8}$. Por lo tanto, el pasado es una construcción temporal que depende de la relación entre Memoria e Historia; en palabras de Walter Benjamín: "el pasado solo es atrapable como la imagen que refulge para nunca más volver, en el instante que se vuelve reconocible".

6 Josefina Cuesta Bustillo, "Memoria e historia, un estado de la cuestión", AYER No. 32 (1998) (http://ww.ahistcon.org/docs/ayer/AYER32_12.pdf). Consultado el 5 de mayo de 2013.

7 Enrique Florescano, "Notas sobre las relaciones entre memoria y nación en la historiografía mexicana", Historia Mexicana, Vol. 53, No. 2 (2003): 391-416.

8 Paul Ricoeur, La memoria, la historia...128.

9 Walter Benjamín, "Tesis de Filosofía de la Historia", en: Ensayos Escogidos, H.A. 
Pero, ¿cuándo el pasado se vuelve reconocible y para quién? Cada historiador pretende explicar el pasado con la excusa de entender el presente; sin embargo, su referencia a ese pasado es parcial y depende de las huellas que se encuentran en la memoria y de la percepción y reflexión del historiador. En términos generales, el vínculo entre pasado y presente -conciencia histórica-reside en la Memoria y en la capacidad del historiador para interpretar el pasado.

Otro punto de esta reflexión es comprender la diferenciación entre Memoria individual y Memoria colectiva y su relación con la Historia. Los primeros estudios que se centraron en explicar el concepto de Memoria, la asociaron principalmente a la forma de acumulación de información como parte de la evidencia que servía de base a los historiadores para construir la verdad. El punto central fue la distinción entre la información de los archivos y la Memoria individual o personal. $\mathrm{Al}$ respecto se debe considerar que buena parte de la información que reposa en los archivos ha sido custodiada para garantizar el tipo de Memoria que se pretende que los grupos sociales retengan y conserven, nos referimos al poder y a los intereses que desde allí se desligan; mientras que la Memoria individual está sujeta a las vivencias, al significado de un hecho y a las experiencias de cada sujeto social, de su historia vivida. Por su parte, la Memoria colectiva se refiere a las formas de representación en que se plantean las vivencias y las experiencias colectivas, es decir, recurriendo a la tesis de Benjamin, al modo en que ese pasado se representa en imágenes, entre los miembros de una colectividad en un momento dado.

En esa relación siempre tensa, siempre cambiante, entre Memoria individual y colectiva, es necesario considerar que la memoria personal actúa como testigo de las experiencias, aunque socialmente condicionada ${ }^{10}$. Un rasgo fundamental de la Memoria colectiva es que está determinada por la política

Múnera (Buenos Aires: El cuenco de Plata, 2010).

10 Aron Cohén, Historia y Memoria colectiva (México: Universidad Nacional Autónoma de México, 1912), 2-3. 
pública, y ésta tiene un instrumento fundamental en lo que Pierre Nora denomina "lugares de la memoria". Estos se consideran "espacios centrales" para establecer la relación del pasado con el presente; a la vez articulan la Historia con la Memoria.

El concepto de Memoria colectiva fue planteado inicialmente por el sociólogo Maurice Halbwachs en la década de los años veinte, sus planteamientos sirvieron de base para que luego, en la década de los años noventa, fuera retomado para referirse a la Memoria colectiva como concepto explicativo de una cierta cantidad de fenómenos sociales. Según Halbwachs ${ }^{11}$, la Memoria es por naturaleza múltiple, colectiva, plural e individualizada; la Memoria se enlaza con lo concreto, con el espacio, con el gesto, con la imagen y con el objeto. Posteriormente Marc Bloch, se refirió al concepto de Memoria como un rasgo central para comprender la estructura social de las sociedades medievales, es decir, a la memoria como parte de la configuración de la sociedad en que están inmersas prácticas y representaciones colectivas.

La tercera generación de Anales, particularmente Jacques Le Goff y Pierre Nora retomaron, desde la historia, el concepto de Memoria como fundamento central para el estudio de los procesos de transición de la oralidad a la escritura ${ }^{12}$. Pierre Nora aportó el concepto central de "lugares de la memoria" para referirse a los espacios que son definidos selectivamente y que durante mucho tiempo han permanecido como símbolos, entre los que podemos resaltar: fiestas, emblemas, monumentos, prácticas sociales y culturales. Esos lugares tienen múltiples dimensiones, y una de ellas es justamente la de contribuir a la construcción de la Historia ${ }^{13}$. El concepto de "lugares de la

11 Maurice Halbwachs, Los marcos sociales de la memoria (Barcelona: Editorial Antropos, 2004). Maurice Halbwachs, La memoria colectiva (Barcelona: Editorial Antropos, 2011).

12 Mauricio Menjívar Ochoa. Los estudios sobre la memoria y los usos del pasado: perspectivas teóricas y metodológicas (Flacso: sede académica de Costa Rica, 2005).

13 Felipe Gómez Isa. El Derecho a la Memoria, 2006, En: http://books.google.com. co/books?id=53aSzGJSFB0C\&printsec=frontcover\&dq=Felipe $+\mathrm{G} \% \mathrm{C} 3 \% \mathrm{~B} 3 \mathrm{mez}+\mathrm{Isa}$ ,+El+Derecho+a+la+Memoria\&hl=es\&sa=X\&ei=tF8lUrDXIsWysASZkoDwAg\&ved 
memoria" representó una ruptura epistemológica ocupándose de la Historia de lo simbólico. En palabras de Pierre Nora, los lugares de la Memoria son aquellos espacios no necesariamente físicos, en que la Memoria se ha encarnado selectivamente y que durante mucho tiempo han permanecido como símbolos. Según Mauricio Menjívar, el concepto aportado por Nora se refiere más a un método que a un concepto propiamente dicho, puesto que sus reflexiones plantean perspectivas distintas y formas de analizar los mecanismos como se produce la memoria. Precisamente el lugar al que se refiere Nora es a la vez el objeto del historiador, traducido en un instrumento cognitivo para su análisis ${ }^{14}$.

Por su parte, desde la perspectiva de Paul Ricoeur, se establece una relación dialéctica entre Memoria e Historia, puesto que la memoria individual puede incidir en la memoria colectiva, a la vez que ciertos fenómenos sociales ayudan a fijar la memoria de los sujetos. Así, la Memoria se convierte en base fundamental para el análisis de las disímiles temporalidades e interrelaciones de los grupos sociales, aporta elementos testimoniales que son fundamentales para caracterizar sujetos y procesos; de esta manera, la Historia no solo se liga a las continuidades temporales, a las evoluciones y relaciones de los sucesos, sino a la comprensión y explicación de los grupos sociales en tiempos y espacios diversos.

En esta relación entre Historia y Memoria salta a la vista el problema de las fuentes como artefactos culturales que no sirven solamente para ver la noción de reflejo de la realidad pasada, sino como mecanismos utilizados como interpretantes del pasado ${ }^{15}$. Así, vista la relación Historia y Memoria, la Historia es una forma de relacionarse desde el presente simbólicamente con el pasado. Al respecto, Hernán

=0CC4Q6AEwAA\#v=onepage \&q=Felipe $\% 20 \mathrm{G} \% \mathrm{C} 3 \% \mathrm{~B} 3 \mathrm{mez} \% 20 \mathrm{Isa} \% 2 \mathrm{C} \% 20 \mathrm{El} \% 20$ Derecho\%20a\%20la\%20Memoria\&f=false, consultado el 15 de abril de 2013.

14 Josefina Cuesta Bustillo, "Memoria e historia,...

15 Astrid Erll. Memoria Colectiva y Cultura del Recuerdo (Bogotá: Universidad de Los Andes, 2012): 54-58. 
Sorgentini ${ }^{16}$ revive el debate entre el pasado y el presente como objeto de estudio de la Historia, en que el pasado es la base para entender el presente y éste debe ser el fundamento de la Historia. Según sus planteamientos el lenguaje es el cimiento de la representación en su máxima expresión, es el elemento que permite explicar e interpretar un proceso de temporalidad cambiante en tiempo y espacio.

Para tratar de encontrar esa relación, un primer aspecto consiste en estudiar las tradiciones "realmente inventadas, construidas y formalmente instituidas", posteriormente tratar de comprender cómo la memoria se utilizó como medio para rescatar la historia de los vencidos, en otros casos se refiere al patrimonio y legitimidad de los excluidos que nos permite encontrar otros protagonistas y otras explicaciones de la sociedad. En segundo lugar comprender que el pasado antes que la memoria o conciencia histórica es un proceso real que determina el presente con independencia de las imágenes que de ese pasado construyen los historiadores, y tratar de comprender sus perspectivas e intencionalidades ${ }^{17}$.

Esto nos permite apreciar cómo el historiador participa en la construcción de la memoria social, porque con el resultado de su investigación pretende aportar nuevas reflexiones sobre un hecho, y en su transmisión puede incidir en la fijación del recuerdo individual y colectivo. Por otra parte, a partir de las fuentes o testimonios utilizados elabora una interpretaciónconocimiento, con el que pretende explicar el pasado como realidad, para luego darlo a conocer a través de su discurso histórico.

En términos generales, la recuperación del pasado puede ser instrumentalizado por quienes pretenden fijar un tipo de dominación, a la vez que puede ser utilizado como mecanismo de control, y tal vez una forma de denuncia o un instrumento

16 Hernán Sorgentini, "Reflexiones sobre la memoria y autorreflexiones de la historia”, Revista Brasilera de Historia, 23. 45 (2003): 103-128.

17 Enrique Florescano, La Historia y el Historiador (México: Fondo de cultura económica, 2003). 
para afianzar la identidad de un grupo determinado. Sin embargo, es importante indagar por la forma como se ha construido el objeto en el tiempo, mirar la construcción de ese hecho histórico y la manera en que se ha transmitido. No se trata solamente de identificar qué pasó, sino de comprender las modalidades del uso de ese conocimiento histórico y sus alcances, y de tratar de percibir cómo el poder es capaz de legitimar el pasado.

\section{Historia y Memoria en debate}

La Revista Historia Y MEMORIA se ha convertido en un medio de reflexión y socialización de experiencias investigativas en el campo de la Historia. Por medio de esta revista se han puesto en diálogo reflexiones historiográficas, epistemológicas, metodológicas en las que el tema de la Memoria en relación con la Historia ha estado presente.

Para explicar el tema de la independencia los autores retomaron concepciones teóricas distintas, otras metodológicas y fuentes que les permitió plantear nuevos debates, a partir de las versiones testimoniales que no se hubieran escuchado y que permanecían en el anonimato; o con otras preguntas y otras categorías de análisis.

Por ejemplo, el tema de las Independencias en América Latina hizo alusión a la Memoria dándoles protagonismo a otros actores sociales, particularmente a las masas. Josep Fontana ${ }^{18}$ invita a comprender el proceso de independencia de América, a partir del análisis de las realidades propias de cada estado, teniendo en cuenta el contexto, las manifestaciones de protesta de los grupos sociales, el definir fronteras de orden territorial, igualmente, el consolidar tipos de administración. La independencia también se analizó desde el uso de lo simbólico para comprender la forma en que se afianzaron las relaciones de poder; en este contexto emergió el concepto de soberanía popular, con una noción de exclusión a un amplio

18 Josep Fontana, "En torno al significado de la independencia", Historia $Y$ MEMORIA, 2, (2011): 11-32. 
número de la población, lo que explica en parte la diversidad de conflictos entre élites locales y regionales ${ }^{19}$. De esta manera, Josep Fontana y Justo Cuño reivindican la memoria de los 'otros' referida a su participación o no en las guerras de independencia, al proyecto de Estado y de nación que se construyó con posterioridad al proceso de emancipación.

Para explicar esta temática, la independencia, se pusieron en diálogo interpretaciones a partir de la memoria de los excluidos, lo que permitiría comprender imperfecciones y proyecciones inconclusas, y ver de qué manera estos estados construyeron identidad y un proyecto político independiente. Los aportes de los autores de estas temáticas coinciden en dar mayor protagonismo a los americanos y a los sectores populares, de esta manera se ponen en consideración la memoria de otros actores sociales que permanecieron en el anonimato. Por ejemplo, al período de 1810-1814 en la Nueva Granada, la historiografía tradicional le dio la denominación de "Patria Boba" y las visiones recientes han planteado otras lecturas, que tienen que ver con el fortalecimiento de las élites regionales, la construcción de proyectos políticos disímiles con el fortalecimiento de las provincias en contradicción al establecimiento de un estado central fuerte, lo que se constituye en una base central para la construcción de los modernos estado ${ }^{20}$. Otro texto reivindica el papel de los criollos americanos en las Juntas de Mérida dando protagonismo al papel de las élites y de sus proyectos políticos ${ }^{21}$; en esta dirección el texto de Juan Manuel Robayo señala que los americanos tuvieron un gran protagonismo en dar autonomía a las provincias y desde allí se construyó una visión de Estado y de sociedad. Sobre la autonomía gubernamental como expresión del proceso de independencia, Reinaldo Rojas ${ }^{22}$ estudia la

19 Justo Cuño Bonito, "Lo real y lo imaginario en la construcción de la República colombiana", Historia Y MEMORIA, 2, (2011): 33-52.

20 Juan Manuel Robayo, "Reflexiones en torno al impacto de la Patria Boba. La independencia de Tunja y su provincia 1810 - 1815”, Historia Y MEMORIA, 1, (2010): 11-34.

21 Edda Otilia Zamudio Aizpurúa, "La experiencia juntista en Mérida (Venezuela). 1808-1811”, Historia Y MEMORIA, 1, (2010): 35-54.

22 Reinaldo Rojas, "La Junta Suprema de Caracas de 1810: Nación, autonomía e 
forma en que se organizó la Junta Suprema de Caracas, que se convirtió en el primer mecanismo de expresión política de los criollos. Aunque inicialmente pretendía defender el gobierno de Fernando VII, esta fue la base para la conformación de las juntas de gobierno autónomas, que paulatinamente proclamaron la independencia y elaboraron los primeros proyectos constitucionales. Con relación a la autonomía política, Jorge Tomás Uribe ${ }^{23}$ se refiere a la tendencia de los constitucionalistas liderada por la élite criolla santafereña, la que promovió la consolidación de las primeras constituciones, inspiradas en las fuentes del derecho medieval español, con el fin de establecer rupturas profundas con el sistema español imperante.

Pero no solamente la independencia se puede estudiar desde lo político. Francisco Bolsi ${ }^{24}$, analizó los negocios que se generaron durante el período de independencia en Argentina, que permite apreciar las redes familiares y de poder que se consolidaron con la nueva élite económica en TucumánArgentina.

Y en el proceso independentista, ¿cómo dejar de lado la participación de los indígenas, la plebe, los afro-descendientes y en general de los sectores populares en el proceso de independencia? Al respecto, Alonso Valencia analiza la forma como los sectores populares participaron en las movilizaciones de la Gobernación de Popayán, lo que condujo a la independencia de esta provincia con la participación de indígenas y afros en los movimientos sociales. Estos sectores, a través de la protesta, asumieron un protagonismo político $\mathrm{y}$, de esta manera, rechazaron las autoridades coloniales y la dominación de las élites en general. Sobre la participación de los sectores populares, igualmente la venezolana Jaika

\footnotetext{
independencia", Historia Y MEMORIA, 2, (2011): 69-92.

23 Jorge Tomás Uribe, "Independencia, Historia y Derecho", Historia Y MEMORIA, 2, (2011): 125-145.

24 Francisco Bolsi, "Negocios, familia y estrategias de producción social entre el Antiguo Régimen y el proceso de Revolución e Independencia en Tucumán, 17801820. El caso de los Posse", Historia Y MEMORIA, 1, (2010): 55-86.
} 
Tejada $^{25}$ hace alusión a la forma en que los blancos, los indios, los pardos y mulatos se incorporaron en el proceso de independencia en la Provincia de Caracas, lo que dio la sensación de ser un conflicto de razas. Por su parte, Marisa Davio $^{26}$ analiza cómo los sectores populares asumieron una nueva cultura política, a partir de su vinculación en la militarización, durante la primera mitad del siglo XIX en Tucumán-Argentina. Los sectores populares que hicieron parte de las tropas experimentaron cambios en su forma de vida, en los roles y en las identidades; su participación en la militarización los incorporó en el espacio público y los llevó a desarrollar una serie de prácticas y acciones de resistencia que incidieron en consolidar un nuevo sujeto político.

Por su parte, Alfredo Cordiviola ${ }^{27}$ estudió las rebeliones indígenas en el Perú en el siglo VIII, las que fueron vistas como nostalgia y como utopía, pero que respondieron a la conformación de un movimiento de resistencia contra el dominio español. Con estas reflexiones, Cordiviola da cuenta de cómo los abusos y las desigualdades de la economía imperial influyeron en fijar en los sectores populares una conciencia política que motivó a consolidar un 'movimiento nacionalista Inca', que se vio reflejada en la insurrección promovida por Túpac Amaru, para lo cual se toma como excusa el drama de Ollantay. En este sentido, los autores nos permiten escuchar las voces de otros actores sociales, que posiblemente estaban invisibilizados por la historiografía tradicional y que dan cuenta de procesos alternativos, identidades y formas de resistencia ante el sistema. De esta manera, el tema de la independencia ha configurado visiones distintas a partir de escuchar otras voces, de retomar otras temáticas y de consultar otras fuentes para el análisis, Así pues, la memoria le permite al historiador comprender los procesos independentistas desde perspectivas distintas.

25 Jaika Tejada Soria, "Pulperos, pardos e independencia en Venezuela 1812-1814", Historia Y MEMORIA, 2, (2011): 53-68.

26 Marisa Davio, "El proceso de Militarización en Tucumán durante la primera mitad del siglo XIX: experiencias e identidades de los sectores populares", Historia Y MEMORIA, 2, (2011): 93-124.

27 Alfredo Cordiviola, "Atribuciones de la Nostalgia: Ollantay y el Movimiento NeoInca”, Historia Y MEMORIA, 1, (2010): 135-158. 
Uno de los temas de mayor controversia en nuestros tiempos es el de las "Revoluciones en América Latina", por tanto es necesario reflexionar sobre la forma como la historia ha construido la memoria sobre las revoluciones. Francisco García ${ }^{28}$ abre un panorama sobre la mirada que tenían los conservadores chilenos sobre las ideas que se desprendieron de la Revolución Francesa, las que en su momento, fueron consideradas "doctrinas funestas" que atentaban contra la unanimidad católica y se les consideró una amenaza para el sistema social establecido en Europa y América, durante el siglo XIX. De esta manera, se asume el ideario de los conservadores como una memoria anti revolucionaria que defiende las relaciones Iglesia-Estado y la conservación del orden monárquico. Entre la ideología y las prácticas de violencia se plantea la "revolución del Llano"29, caso particular de Villavicencio-Colombia donde la violencia asumió características particulares en que la lucha por el poder regional y local en 1947 y 1948 entre élites liberales y conservadoras, fue el garante para que los sectores populares -excluidos-, se identificaran con la categoría de pueblo y desde su condición marginal, se convirtió en una fuerza en oposición a la 'oligarquía', así, se consolidó en Villavicencio un movimiento popular independiente al tradicionalismo político, con pretensiones revolucionarias.

Desde otra perspectiva se analiza la influencia de la revolución cultural francés de 1968 en los movimientos estudiantiles $^{30}$, en que la memoria le da el protagonismo a otros actores sociales, los estudiantes, que le aportaron a los movimientos sociales formas de interpretación de la sociedad, tácticas de organización y en general proyectos políticos que en ocasiones se asocian a ideologías de izquierda. Escuchar estas voces de los sectores populares desde visiones distintas

28 Francisco García Naranjo, "El Abismo Francés. Los conservadores chilenos y la Francia revolucionaria, 1864-1890", Historia Y MEMORIA, 3, (2011): 13-44.

29 Andrés Gómez, "Elecciones y junta revolucionaria. Villavicencio 1947-1948", Historia Y MEMORIA, 3, (2011): 79-108.

30 Álvaro Acevedo Tarazona y Gabriel Samacá Alonso, "El Movimiento estudiantil como objeto de estudio en la historiografía colombiana y continental: notas para un balance y una agenda de investigación”, Historia Y MEMORIA, 3, (2011): 45-78. 
permite plantear un diálogo sobre el significado de la revolución en tiempos y contexto distintos, sin perder de vista los recuerdos y percepciones de los diversos actores sociales en relación con la memoria.

La "historia de las mujeres" no ha sido ajena a las reflexiones. Algunos estudiosos han encontrado en la historia de las mujeres una representación y explicación a procesos sociales. Jane Meyer ${ }^{31}$, estudió los escritos de tres mujeres norteamericanas que narraron visiones distintas sobre la sociedad y la cultura de los colombianos entre 1920-1950, resalta la percepción de las mujeres norteamericanas sobre la sociedad colombiana resaltando el paisaje y algunas actividades culturales propias del momento, lo que aporta una visión novedosa sobre el pensamiento y la representación que tenían las mujeres sobre la sociedad colombiana de la época. La pregunta: ¿por qué las mujeres han sido invisibilizadas en la enseñanza de la historia? ${ }^{32}$ conlleva a la reflexión sobre el currículo de ciencias sociales y particularmente de historia en Cataluña. El texto indaga por la memoria que han construido los estudiantes de "enseñanza secundaria obligatoria" sobre el papel de las mujeres en la historia, la investigación les permitió concluir que la presencia de las mujeres es casi nula; la hipótesis que construyen los autores es que posiblemente la enseñanza de la historia sigue ligada a la historia política tradicional, por eso la imagen de la mujer es como heroína, princesa, bruja o feminista. Desde otra mirada, Julieta Quezada ${ }^{33}$ aborda la participación de las mujeres michoacanas en la guerra de los cristeros; a través de sus reflexiones, la autora señala que las mujeres participaron activamente en el conflicto como proveedoras de armas, municiones, y como informantes y practicantes del culto católico, de esta manera se otorgó un papel central al protagonismo político de la mujer en el conflicto religioso que plantea una memoria distinta.

31 Jane Meyer, "Con los ojos de ellas: percepciones de la historia en Colombia 1920-1950, a partir de las narraciones de tres mujeres norteamericanas", Historia $Y$ MEMORIA, 3, (2011): 111-128.

32 Edda Sant Obiols y Jean Pagés Blanch, “Por qué las mujeres son invisibles en la enseñanza de la historia?", Historia Y MEMORIA, 3, (2011): 129-146.

33 Claudia Julieta Quezada Quiroz, "La mujer cristera en Michoacán, 1926-1929", Historia Y MEMORIA, 4, (2012):191-223. 
Por su parte, María Teresa Patiño ${ }^{34}$, estudió las conductas sociales irregulares o delitos de los que fueron víctimas las mujeres, violación y estupro, en la Provincia de Tunja entre 1800 y 1820; se refiere a las sanciones y castigos establecidas en las leyes indianas, a la caracterización de los demandantes y los demandados, sin dejar de lado la descripción de las conductas de víctimas y victimarios. La reivindicación de este artículo es sustancial porque permite apreciar la voz de las víctimas, mujeres, que posiblemente fueron invisibilizadas por su condición de género o por su condición social.

Imagen y memoria visual. Ha suscitado la reflexión de los historiadores, que desde diversas perspectivas nos aportan elementos teóricos y metodológicos para el análisis de la imagen y de las representaciones sociales. Un primer texto se refiere a la forma como se construye la imagen del héroe-niño y mártir de la independencia colombiana, la configuración de esta imagen se inició con las pinturas y dibujos de José María Espinosa, con las que se pretende generar identidad en los colombianos ${ }^{35}$. Así, la imagen de Antonio Ricaurte como héroe, fue utilizada por los gobiernos conservadores y por la Iglesia durante "La Regeneración" y la hegemonía conservadora para tratar de promover identidad nacional. Y sobre la representación de la Villa Imperial de Potosí, considerada en el siglo XVIII como una de las ciudades más grandes de esta región, la representación de esta ciudad "generó una iconografía que pasó de la representación de su cerro como generador de estructuras de clase/raza o a su unión con la virgen", con lo que posiblemente se pretendió construir un mito ${ }^{36}$, esto le permite al autor explicar cómo la decadencia de la economía en la Villa Imperial de Potosí se traslada a una relación mitológica, que logra una imbricación entre cuerpo y territorio, y estas imágenes asumen otra connotación cultural.

34 María Teresa Patiño, "Delitos en torno al núcleo familiar. Delitos contra las mujeres", Historia Y MEMORIA, 5, (2012): 201-223.

35 Abel Fernando Martínez Martín y Andrés Ricardo Otálora Cascante, "Antonio Ricaurte. La creación de la imagen de un héroe niño 1830-1881", Historia Y MEMORIA, 4, (2012):13-44.

36 Francisco Antonio Godoy Vega, "Anatomías Territoriales. Alternativas de activar la otredad de pinturas coloniales de Potosí", Historia Y MEMORIA, 4, (2012): 45-91. 
El tema de la violencia y la representación es retomado por María Luisa Ortega ${ }^{37}$, que se refiere a la memoria de la violencia durante la dictadura en Argentina, cuyos rastros quedaron registrados en lugares, objetos y cuerpos, que se pueden ver a través de la fotografía, el cine y otras formas de expresión artísticas, vistas a partir de las expresiones de la corporalidad de los desaparecidos, analizando la representación de las víctimas de la violencia y el dolor; y la resignificación de la temporalidad a través de los estudios sobre la memoria. Aquí la memoria es asumida desde las representaciones del cuerpo de las víctimas, por lo que tanto la temática como el uso de las fuentes aportan elementos sustanciales para comprender la compleja relación entre historia y memoria. Y sobre la representación del cuerpo, David Moriente ${ }^{38}$ estudia las estrategias de representación y apropiación que utiliza la artista brasileña Adriana Varejao en su producción pictórica. Moriente analiza un número significativo de referencias visuales y se centra en el estudio de lo corporal, particularmente en el simbolismo de la carne humana, lo que se aborda desde los procesos de hibridación o criollización cultural.

La memoria en las conmemoraciones. El Bicentenario de la independencia ha sido una excusa para retomar temas y problemas como el de las constituciones. Se retomó la memoria sobre la consolidación de las Juntas revolucionarias de gobierno que se conformaron en América española entre 1808 y 1810. Víctor Uribe ${ }^{39}$ dice que las constituciones se convirtieron en la expresión moderna de 'acuerdo colectivo', que a la vez planteó un proyecto de organización social. Para algunos autores el protagonismo lo tienen ciertos líderes políticos locales en las discusiones y propuestas sobre el establecimiento del primer

37 María Luisa Ortega, "Temporalidades en conflicto: cuerpo y desaparición en las prácticas artísticas contemporáneas en Argentina", Historia Y MEMORIA, 4, (2012): 93-140.

38 David Moriente, "Un planeta Caníbal", Historia Y MEMORIA, 4, (2012): 141187.

39 Víctor Uribe Urán, "Insurgentes de provincia: Nueva Granada y el constitucionalismo en el mundo Hispánico en la década de 1810", Historia Y MEMORIA, 5, (2012): 17-48. 
gobierno republicano ${ }^{40}$, para el caso de México se analizó el protagonismo de Vicente Guerrero, quien introdujo en la constitución de este país, los conceptos de poder y legitimidad con el fin de mantener y controlar sus fuerzas de apoyo, estas fueron las bases de un proyecto de república independiente ${ }^{41}$.

Por otra parte, la conmemoración es un medio fundamental para fijar un tipo de memoria que se convertiría en rasgo fundamental de la identidad y de las representaciones sociales. La memoria fue abordada desde la relación entre patrimonio y territorio en el Bicentenario, lo que llevó a Andrés Castiblanco, ${ }^{42}$ a plantear que estos elementos fueron constitutivos de la identidad social del colombiano, precisamente el significado del 20 de julio reflejó, tal vez, una ruptura con el antiguo régimen. Y sobre la memoria del centenario Abel Martínez y Andrés Otálora ${ }^{43}$ describen cómo se celebraron las fiestas en el primer centenario de independencia nacional y de la Provincia de Tunja, estas celebraciones se fundamentaron en el concepto de patria y establecieron una articulación entre la nueva nación y la metrópoli; con este proyecto de nación se perfiló el progreso, la modernidad y la paz de los boyacenses. Aquí se analiza el cómo se configura memoria colectiva o, como lo plantea Nora, de qué manera se instrumentalizan las fiestas patrias para pretender crear identidad o un lugar común, "lugares de la memoria".

Los excluidos y la memoria. Ángela Camargo $0^{44}$ estudia la organización y composición de las fuerzas armadas

40 Armando Martínez Garnica, "José Joaquín Camacho y su influencia en la constitución de la Provincia de Tunja (1811)”, Historia Y MEMORIA, 5, (2012):73111.

41 Eduardo Miranda Arrieta, "La causa de la independencia y la República. Vicente Guerrero, un insurgente mexicano frente a la revivida Constitución Española en 1820", Historia Y MEMORIA, 5, (2012):49-72.

42 Andrés F. Castiblanco Roldán, "El bicentenario en Colombia. Memoria, Patrimonio y Territorio", Historia Y MEMORIA, 1, (2010): 113-133.

43 Abel Fernando Martínez Martín y Andrés Ricardo Otálora Cascante, "Patria y Madre Patria. Las fiestas centenarias de 1910 y 1911 en Tunja", Historia Y MEMORIA, 5, (2012): 115-143.

44 Ángela Patricia Camargo Rodríguez, "La Institución militar en el estado de Magdalena 1857-1885”, Historia Y MEMORIA, 3, (2011): 147-168. 
en el Estado soberano del Magdalena en el período federal, 1863-1886. Durante este período los gobiernos locales institucionalizaron una fuerza legítima capaz de defender el orden público del Estado, lo que se derivó de la ideología liberal con que se pretendía defender la integridad pública; a través de este texto se puede apreciar la participación de los sectores populares en el ejército, lo que entra en contradicción con la perspectiva tradicional de que el ejército es una fuerza de élite consolidada por las élites, desde allí la visión de la memoria está relacionada con el papel de los sectores populares en la participación militar y en la construcción de un proyecto colectivo.

Los excluidos fueron estudiados también por Ricardo Chica y Olga Acuña ${ }^{45}$, que analizan la influencia del cine mexicano, en su época de oro, en la reconfiguración de la cultura popular en los sectores populares de Cartagena; se resalta cómo los saberes culturales fueron codificados a través del melodrama, sus arquetipos y actuaciones, con los que los sectores populares adoptaron nuevos sentimientos y estilos que incidieron en la vida cotidiana de los habitantes de los sectores populares de Cartagena. En este texto el uso de fuentes iconográficas, particularmente del cine, aporta elementos sustanciales de la memoria de los sectores populares, lo que es sustancial para comprender la caracterización, representatividad y reconfiguración de las prácticas culturales en los sectores populares.

Memoria y proyectos políticos. Y sobre el problema del Estado y los regímenes políticos latinoamericanos, María Celia Bravo ${ }^{46}$ analiza las tendencias del federalismo argentino entre 1830 y 1880 , en función de las fuerzas cambiantes entre las provincias y el incipiente Estado central; este movimiento osciló entre la disolución del orden colonial, la reivindicación

45 Ricardo Chica Geliz y Olga Yanet Acuña Rodríguez, "Cinema Reporter y la reconfiguración de la Cultura popular de Cartagena de Indias 1936-1957”, Historia Y MEMORIA, 3, (2011): 169-199.

46 María Celia Bravo, "Los sentidos de la Nación y el federalismo en la Argentina 1830-1880”, Historia Y MEMORIA, 6, (2013): 205-232. 
de la soberanía de las ciudades y la conformación de un movimiento federal con perspectiva totalizadora con el fin de unir a las provincias.

La memoria sobre la construcción de ciudadanía ha sido tema de interés, en ese sentido Edwin Monsalvo ${ }^{47}$ estudió el problema de las elecciones y de la construcción de ciudadanía en Cartagena, centrándose principalmente en los debates que sobre ciudadanía se suscitaron en los primeros años de la república 1810-1834, y en las relaciones de inclusión/exclusión, enfatizando en quienes podían votar y en los requisitos; en términos generales los fundamentos se centraron en la libertad del sufragio y en la independencia del votante, porque precisamente son otros los actores y tal vez más los excluidos los que participan desde la ilegalidad.

Desde la historia local, María Teresa Álvarez analiza el proceso de modernización de Pasto, desde el entorno urbano y la comunicación e integración con el resto del país y con el extranjero. Con la celebración del primer centenario de la independencia se promovió una movilización que reclamaba la creación del ferrocarril de Nariño y el mejoramiento de las condiciones de vida urbana. De esta manera, se plantea cómo los actores sociales pastusos promovieron la modernización de la ciudad de Pasto bajo un proyecto de celebración del primer centenario, con el fin de reivindicar la identidad del pastuso y la colombianidad bajo la perspectiva de modernización.

Como parte de los proyectos políticos, se estudia el establecimiento del proyecto de Regeneración en Colombia, el caso del Departamento de Boyacá, con el que se pretendió consolidar un proyecto de nación mediante el establecimiento de un estado fuerte, bajo la perspectiva de centralización del poder, para lo cual se instrumentalizó la religión, la educación y el lenguaje como elementos centrales para la conformación de un proyecto de unidad nacional ${ }^{48}$.

47 Edwin Monsalvo Mendoza, "Ciudadanía, Vecindad y sufragio en Cartagena 1810-1834”, Historia Y MEMORIA, 6, (2013): 171-204.

48 Claudia Liliana Monroy, "El Departamento de Boyacá a partir del proyecto 
Desde la memoria en la consolidación de la política regional, Olga Yanet Acuña ${ }^{49}$ analiza el tema de los partidos y directorios políticos, toma el caso del Departamento Boyacá, se refiere a cómo los partidos y directorios políticos transformaron las relaciones sociales y políticas en esta región, teniendo en cuenta que éstos fueron la base del sistema político, a la vez que se convirtieron en escenario de sociabilidad política, lo que favoreció que los sectores populares y excluidos asumieran la participación, la representatividad y una posición política. En el contexto de la historia política local, Fabio Santos ${ }^{50}$ examina, desde una perspectiva historiográfica, cómo se ha estudiado el tema de los partidos y movimientos políticos en el contexto local y latinoamericano, así como de las elecciones, formas de participación y representatividad con el fin de contextualizar el sistema colombiano. Así, Santos plantea una reflexión distinta de la forma como se construye cultura política y cómo se aborda el tema de la política en el entorno local y regional.

Y sobre la memoria de actores y prácticas, Wilson Márquez ${ }^{51}$, describe "el establecimiento de la pena de muerte en Colombia como semiología del castigo y del teatro punitivo desde finales del régimen colonial hasta principios del siglo XX”. Desde un punto de vista jurídico la pena de muerte fue un mecanismo de control social, entre su aparición y desaparición es importante establecer el uso político que sirvió como mecanismo para la eliminación del enemigo político. Por eso la memoria de los "otros" o de las víctimas es un punto central para la comprensión de los procesos sociales.

político de la Regeneración 1886-1903. Reflexiones desde lo político-administrativo, educativo y religioso", Historia Y MEMORIA, 1, (2010): 159-179.

49 Olga Yanet Acuña Rodríguez, "Partidos y Directorios, formas de sociabilidad política en Boyacá 1930-1953. Escenarios de construcción de nación”, Historia Y MEMORIA, 2, (2011): 147-175.

50 Fabio Santos Hernández, "Elecciones y partidos políticos. Una aproximación al balance historiográfico desde el contexto latinoamericano", Historia Y MEMORIA, 5, (2012): 225-255.

51 José Wilson Márquez Estrada, "La Nación en el Cadalso. Pena de Muerte y politización del patíbulo en Colombia: 1800-1910”, Historia Y MEMORIA, 5, (2012): 145-178. 
Tierra y memoria. En la memoria de muchos habitantes el tema de la tierra les genera inconformismo, desolación e incertidumbre porque consideran que la tierra es parte de su identidad y de su expresión cultural, por eso se ha dedicado un espacio para reflexionar sobre la propiedad y distribución de la tierra, asimismo comprender el valor que los diversos grupos sociales le han dado a la tierra, ya desde lo económico, lo social, lo político o lo cultural. Al respecto, Egilda Rangel ${ }^{52}$ estudia el proceso de incorporación de la tierra al dominio privado iniciado en la segunda mitad del siglo XVI, en el actual territorio de Venezuela. A lo largo de este proceso se pudieron apreciar litigios, relaciones comerciales de compra y venta y la permanencia de unas familias, que a través de los mayorazgos se convirtieron en la élite venezolana. Por otra parte, la tenencia de la tierra desde la colonia hasta la república estuvo en manos de la familia Ponte y Villegas, con lo que se pudo establecer una permanencia en la prevalencia de grupos de poder en Venezuela que no es ajeno a otros contextos.

En el caso colombiano el problema de la tierra está ligado a la colonización de tierras, como lo plantea Albeiro Valencia $^{53}$ al referirse a la región del sur de Antioquia donde se produjeron dos tipos de colonización: la de los campesinos pobres y la colonización empresarial; estas formas de colonización generaron conflictos entre colonos, entre colonos e indígenas y sobre todo con los dueños de los latifundios. El tema de la colonización en general se ha referido a la colonización empresarial por considerarla parte del desarrollo, dejando de lado el estudio de aquellos actores sociales, que según su condición de pobreza migraron para encontrar una esperanza de vida.

Y sobre un período más reciente, Josué Villavicencio analiza el caso mexicano y particularmente en la sierra sur de Oaxaca, una zona con alto índice de pobreza, analfabetismo

52 Egilda Rangel, "El Mayorazgo de Sartenejas en la Venezuela Colonial 17401858”, Historia Y MEMORIA, 6, (2013): 17-39.

53 Albeiro Valencia, "Campesinos pobres y señores de la tierra. Migraciones hacia el sur de Antioquia 1800-1900”, Historia Y MEMORIA, 6, (2013): 41-66. 
y falta de protección del estado; estas características han generado una vulnerabilidad en los diversos grupos sociales donde los conflictos agrarios se han ido incrementando puesto que esta región ha sido proclive a la explotación y tráfico ilegal; y sus habitantes víctimas del conflicto armado, disfrazado en un endémico conflicto agrario; de esta manera, se pretende escuchar la voz de las víctimas que tienen una versión distinta sobre lo que han vivido por falta de la presencia del Estado y por la corrupción judicial.

La memoria en la labor de ciertos actores sociales. Desde la historia social uno de los temas poco abordados es el de los oficios. Al respecto, Diana Bonet ${ }^{54}$ caracteriza la forma de organización y el personal que laboraba en la casa de la moneda de Santafé entre 1620 y 1816. Para explicar este proceso, la autora se refiere a dos períodos que oscilan entre la asignación de los oficios a personas particulares y el nombramiento directo de la corona sobre la casa de la moneda; para la designación se tuvieron en cuenta, entre otros, las relaciones de parentesco y el monopolio de los cargos y, aunque se experimentaron cambios en la forma de administración de la casa de la moneda hubo algunas prácticas que permanecieron, entre éstas la designación en el cargo por relaciones de parentesco y la condición vitalicia.

Desde otra mirada, María Eugenia Osorio ${ }^{55}$ describe las prácticas médicas que practicaban los misioneros de la Compañía de Jesús para realizar curaciones; precisamente la botica se convirtió en un tipo de "laboratorio urbano" para curar enfermedades del cuerpo y de la mente. Uno de los aportes centrales al tema de la memoria es establecer la importancia del intercambio de conocimientos en las prácticas de curación utilizadas por los jesuitas y por los nativos americanos, lo que fue fundamental para el establecimiento del "galenismo

54 Diana Inés Bonnett Vélez, "Oficios, rangos y parentesco. Los trabajadores de la Casa de la Moneda de Santafé 1620-1816”, Historia Y MEMORIA, 6, (2013): 103-141. 55 María Eugenia Osorio Oliveros, "La botica neogranadina de la Compañía de Jesús: un laboratorio para explorar prácticas médicas en la provincia de Santafé, primera mitad del siglo XVIII", Historia Y MEMORIA, 6, (2013):143-169. 
humanista", de esta manera se pudo apreciar un sincretismo en las prácticas de curación entre la medicina de occidente-los jesuitas-, y la de los nativos. El reconocimiento de la medicina de los nativos a los españoles es un aporte sustancial porque permite ver una interrelación de saberes y prácticas que son usadas para la curación de enfermedades.

\section{Conclusiones}

Pero ¿cómo se ha construido la historia? Al respecto se han planteado debates que son sustanciales para el historiador y para la construcción del discurso histórico. Renán Silva ${ }^{56}$ reflexiona sobre el uso de teorías y métodos utilizados en la investigación en Ciencias Sociales y en Historia, lo que traslada a un escenario distinto el debate tradicional entre los conceptos y las fuentes. Silva retoma los aportes de Michel Foucault para señalar otras estrategias de análisis en la construcción de la historia.

De esta manera, Historia Y MEMORIA ha abierto un espacio para el debate en que tienen cabida diversas temáticas, metodologías y estrategias. Es importante ver cómo la memoria se encuentra en los aportes testimoniales que ofrecen las fuentes, en la forma de escuchar y reflexionar sobre las diferentes voces que percibimos de las fuentes. En este sentido el concepto de memoria al que nos hemos referido va más allá de las víctimas del conflicto, consideramos que hay otros temas y actores sociales que queremos colocar en debate, nos referimos a los excluidos, a las representaciones sociales, a las relaciones de poder, a los saberes populares, a las prácticas tradicionales, a expresiones culturales, al sentir del 'otro' frente a las manifestaciones de poder. Para este tipo de análisis se hace necesario acudir a teorías y metodologías de las ciencias sociales y humanas que le permitan al investigador comprender las diversas voces que hacen parte de los procesos sociales.

56 Renán Silva Olarte, "En defensa de un positivismo alegre. Michel Foucault en el archivo", Historia Y MEMORIA, 4, (2012): 225-257. 
Así, la memoria individual y colectiva es una construcción que tiene que ver con las vivencias, con la experiencia, con el saber y sobre todo con las pretensiones de los actores y grupos que ostentan el poder. Las diversas temáticas abordadas en estos seis números son un referente que permite poner en diálogo a los historiadores y a los investigadores de las ciencias sociales, donde la Historia analiza las diversas expresiones de la sociedad a partir de las expresiones de la memoria.

Las temáticas abordadas en estos seis números han aportado lecturas sobre los procesos sociales bajo otras concepciones teóricas como los excluidos, que permiten dar protagonismo y visibilizar el papel de ciertos grupos como soldados, mujeres, trabajadores, artesanos, y en general ciertos grupos que la historiografía tradicional los condenó al anonimato. De esta manera, abrimos un espacio para promover debates historiográficos en que se reconozca la memoria de los otros, de los proyectos alternativos a los que se ha restado importancia por considerar, posiblemente, que están en contradicción con el orden establecido.

Las temáticas convocadas en la sección especial de la revista han permitido conocer procesos en tiempos y espacios diversos. Estas temáticas han servido de excusa para generar un diálogo sobre los desarrollos particulares de una región y ponerlos en el contexto nacional e internacional. Así se ha puesto en escena procesos, actores y metodologías diversas que permiten tener un referente y acercarse a una problemática especial. Mientras la sección libre ha tocado temas diversos que permiten socializar la producción historiográfica en el contexto del conocimiento. Por su parte, la sección de reseñas y debates ha generado expectativa, puesto que sus reflexiones pretenden llegar a un público más amplio que desde ópticas distintas plantea revisiones historiográficas.

Finalmente la revista ha abierto un espacio importante para dialogar sobre la producción historiográfica, hasta el momento ha considerado la memoria como un eje transversal tanto en el protagonismo de los actores, como con el uso de las fuentes y por su puesto en la construcción narrativa. Esperamos 
que Historia Y MEMORIA siga siendo un espacio académico en que se ponen en diálogo perspectivas historiográficas diversas que motivan a la reflexión y al debate.

\section{Bibliografía}

Acevedo Tarazona, Álvaro y Samacá Alonso, Gabriel. "El Movimiento estudiantil como objeto de estudio en la historiografía colombiana y continental: notas para un balance y una agenda de investigación”, Historia Y MEMORIA, 3, (2011): 45-78.

Acuña Rodríguez, Olga Yanet. "Partidos y Directorios, formas de sociabilidad política en Boyacá 1930-1953. Escenarios de construcción de nación", Historia Y MEMORIA, 2, (2011): 147-175.

Benjamín, Walter. "Tesis de Filosofía de la Historia", Ensayos Escogidos, H.A. Múnera. Buenos Aires: El cuenco de Plata, 2010.

Bolsi, Francisco. "Negocios, familia y estrategias de producción social entre el Antiguo Régimen y el proceso de Revolución e independencia en Tucumán, 1780-1820. El caso de los Posse", Historia Y MEMORIA, 1, (2010): 55-86.

Bonnett Vélez, Diana Inés. "Oficios, rangos y parentesco. Los trabajadores de la Casa de la Moneda de Santafé 1620-1816", Historia Y MEMORIA, 6, (2013): 103-141.

Bravo, María Celia. "Los sentidos de la Nación y el federalismo en la Argentina 1830-1880", Historia Y MEMORIA, 6, (2013):205232.

Camargo Rodríguez, Ángela Patricia. "La Institución militar en el Estado de Magdalena 1857-1885”, Historia Y MEMORIA, 3, (2011): 147-168.

Castiblanco Roldán, Andrés F. "El bicentenario en Colombia. Memoria, Patrimonio y Territorio", Historia Y MEMORIA, 1, (2010): 113-133.

Chica Geliz, Ricardo y Acuña Rodríguez, Olga Yanet. "Cinema

Reporter y la reconfiguración de la Cultura popular de 
Cartagena de indias 1936-1957”, Historia Y MEMORIA, 3, (2011): 169-199.

Cohén, Aron. Historia y Memoria colectiva. México: Universidad Nacional Autónoma de México, 1912.

Cordiviola, Alfredo. "Atribuciones de la Nostalgia: Ollantay y el Movimiento Neo- Inca”, Historia Y MEMORIA, 1, (2010): 135158.

Cuesta Bustillo, Josefina. "Memoria e historia, un estado de la cuestión”, AYER 32*1998 (http://ww.ahistcon.org/docs/ayer/ AYER32_12.pdf). Consultado el 5 de mayo de 2013.

Cuño Bonito, Justo. "Lo real y lo imaginario en la construcción de la República colombiana", Historia Y MEMORIA, 2, (2011): 33-52.

Davio, Marisa. "El proceso de Militarización en Tucumán durante la primera mitad del siglo XIX: experiencias e identidades de los sectores populares", Historia Y MEMORIA, 2, (2011): 93-124.

Erll, Astrid. Memoria Colectiva y Cultura del Recuerdo. Bogotá: Universidad de Los Andes, 2012.

Florescano, Enrique. La Historia y el Historiador. México: Fondo de cultura económica, 2003.

"Notas sobre las relaciones entre memoria y nación en la historiografía mexicana", Historia Mexicana, 53.2 (2003): 391-416.

Fontana, Josep. "En torno al significado de la independencia", Historia Y MEMORIA, 2, (2011): 11-32.

García Naranjo, Francisco. "El Abismo Francés. Los conservadores chilenos y la Francia revolucionaria, 1864-1890", Historia $Y$ MEMORIA, 3, (2011): 1344.

Godoy Vega, Francisco Antonio. "Anatomías Territoriales. Alternativas de activar la otredad de pinturas coloniales de Potosí", Historia Y MEMORIA, 4, (2012): 45-91. 
Gómez, Andrés. "Elecciones y junta revolucionaria. Villavicencio 1947-1948”, Historia Y MEMORIA, 3, (2011): 79-108.

Gómez Isa, Felipe. El Derecho a la Memoria, 2006, En: http://books. google.com.co/books?id=53aSzGJSFB0C\&printsec=frontcove r\&dq=Felipe+G\%C3\%B3mez+Isa,+El+Derecho+a+la+Memo ria\&hl=es\&sa $=X \& e i=t F 81 U r D X I s W y s A S Z k o D w A g \& v e d=0 \mathrm{C}$ $\mathrm{C} 4 \mathrm{Q} 6 \mathrm{AEwAA \#} \mathrm{v}=$ onepage\&q=Felipe $\% 20 \mathrm{G} \% \mathrm{C} 3 \% \mathrm{~B} 3 \mathrm{mez} \% 20$ Isa $\% 2 \mathrm{C} \% 20 \mathrm{El} \% 20 \mathrm{Derecho} \% 20 \mathrm{a} \% 20 \mathrm{la} \% 20$ Memoria\&f=false, consultado 15 de abril de 2013.

Halbwachs, Maurice. La memoria colectiva. Barcelona: Editorial Antropos, 2011.

. Los marcos sociales de la memoria. Barcelona: Editorial Antropos, 2004.

Márquez Estrada, José Wilson. "La Nación en el Cadalso. Pena de Muerte y politización del patíbulo en Colombia: 1800-1910", Historia Y MEMORIA, 5, (2012): 145-178.

Martínez Garnica, Armando. "José Joaquín Camacho y su influencia en la constitución de la Provincia de Tunja (1811)”, Historia $Y$ MEMORIA, 5, (2012):73-111.

Martínez Martín, Abel Fernando y Otálora Cascante, Andrés Ricardo. "Antonio Ricaurte. La creación de la imagen de un héroe niño 1830-1881”, Historia Y MEMORIA, 4, (2012):1344.

. "Patria y Madre Patria. Las fiestas centenarias de 1910 y 1911 en Tunja”, Historia Y MEMORIA, 5, (2012): 115-143.

Menjívar Ochoa, Mauricio. Los estudios sobre la memoria y los usos del pasado: perspectivas teóricas y metodológicas. Flacso: sede académica de Costa Rica, 2005.

Meyer, Jane. "Con los ojos de ellas: percepciones de la historia en Colombia 1920-1950, a partir de las narraciones de tres mujeres norteamericanas", Historia Y MEMORIA, 3, (2011): 111-128.

Miranda Arrieta, Eduardo. "La causa de la independencia y la República. Vicente Guerrero, un insurgente mexicano frente 
a la revivida Constitución Española en 1820", Historia Y MEMORIA, 5, (2012):49-72.

Monroy, Claudia Liliana. "El Departamento de Boyacá a partir del proyecto político de la Regeneración 1886-1903. Reflexiones desde lo político-administrativo, educativo y religioso", Historia Y MEMORIA, 1, (2010):159-179.

Monsalvo Mendoza, Edwin. "Ciudadanía, Vecindad y sufragio en Cartagena 1810-1834”, Historia Y MEMORIA, 6, (2013): 171204.

Moriente, David. "Un planeta Caníbal", Historia Y MEMORIA, 4, (2012): 141-187.

Ortega, María Luisa. "Temporalidades en conflicto: cuerpo y desaparición en las prácticas artísticas contemporáneas en Argentina”, Historia Y MEMORIA, 4, (2012): 93-140.

Osorio Oliveros, María Eugenia. "La botica neogranadina de la Compañía de Jesús: un laboratorio para explorar prácticas médicas en la provincia de Santafé, primera mitad del siglo XVIII", Historia Y MEMORIA, 6, (2013):143-169.

Patiño, María Teresa. "Delitos en torno al núcleo familiar. Delitos contra las mujeres", Historia Y MEMORIA, 5, (2012): 201-223.

Quezada Quiroz, Claudia Julieta. "La mujer cristera en Michoacán, 1926-1929”, Historia Y MEMORIA, 4, (2012):191-223.

Rangel, Egilda. "El Mayorazgo de Sartenejas en la Venezuela Colonial 1740-1858", Historia Y MEMORIA, 6, (2013): 17-39.

Ricoeur, Paul. La memoria, la historia, el olvido. Madrid: Editorial Trotta, 2003.

Robayo, Juan Manuel. "Reflexiones en torno al impacto de la Patria Boba. La independencia de Tunja y su provincia 1810-1815", Historia Y MEMORIA, 1, (2010): 11-34.

Rojas, Reinaldo. "La Junta Suprema de Caracas de 1810: Nación, autonomía e independencia", Historia Y MEMORIA, 2, (2011): 69-92. 
Sant Obiols, Edda y Pagés Blanch, Jean. “Por qué las mujeres son invisibles en la enseñanza de la historia?", Historia $Y$ MEMORIA, 3, (2011): 129-146.

Santos Hernández, Fabio. "Elecciones y partidos políticos. Una aproximación al balance historiográfico desde el contexto latinoamericano", Historia Y MEMORIA, 5, (2012): 225-255.

Silva Olarte, Renán. "En defensa de un positivismo alegre. Michel Foucault en el archivo", Historia Y MEMORIA, 4, (2012): 225257.

Sorgentini, Hernán. "Reflexiones sobre la memoria y autorreflexiones de la historia", Revista Brasilera de Historia, 23. 45 (2003): 103-128.

Tejada Soria, Jaika. "Pulperos, pardos e independencia en Venezuela 1812-1814", Historia Y MEMORIA, 2, (2011): 53-68.

Uribe, Jorge Tomás. "Independencia, Historia y Derecho", Historia Y MEMORIA, 2, (2011): 125-145.

Uribe Urán, Víctor. "Insurgentes de provincia: Nueva Granada y el constitucionalismo en el mundo Hispánico en la década de 1810", Historia Y MEMORIA, 5, (2012): 17-48.

Valencia, Albeiro. "Campesinos pobres y señores de la tierra. Migraciones hacia el sur de Antioquia 1800-1900", Historia $Y$ MEMORIA, 6, (2013): 41-66.

Zamudio Aizpurúa, Edda Otilia. "La experiencia juntista en Mérida (Venezuela). 1808-1811”, Historia Y MEMORIA, 1, (2010): 3554.

\section{Citar este artículo:}

Olga Yanet Acuña Rodríguez, "El pasado. Historia o Memoria", Revista Historia y Memoria, No. 9 (julio-diciembre, 2014): 57-87. 